\title{
A Pareto-based multi-objective optimization algorithm to design energy-efficient shading devices
}

\author{
Marina Khoroshiltseva ${ }^{\mathrm{a}, *}$, Debora Slanzi ${ }^{\mathrm{b}, \mathrm{a}}$, Irene Poli ${ }^{\mathrm{b}, \mathrm{a}}$ \\ a European Centre for Living Technology, Ca' Minich, S. Marco 2940, 30124 Venice, Italy \\ b Department of Environmental Science, Informatics and Statistics, University Ca' Foscari, Cannaregio 873, 30121 Venice, Italy
}

\section{H I G H L I G H T S}

-We present a multi-objective optimization algorithm for shading design.

- We combine Harmony search and Pareto-based procedures.

- Thermal and daylighting performances of external shading were considered.

- We applied the optimization process to a residential social housing in Madrid.

\section{A R T I C L E I N F O}

\section{Article history:}

Received 20 November 2015

Received in revised form 20 April 2016

Accepted 1 May 2016

Available online $\mathrm{xxxx}$

\section{Keywords:}

Energy efficiency

Multi-objective optimization

Harmony search

Shading design

Thermal and lighting comfort

\begin{abstract}
A B S T R A C T
In this paper we address the problem of designing new energy-efficient static daylight devices that will surround the external windows of a residential building in Madrid. Shading devices can in fact largely influence solar gains in a building and improve thermal and lighting comforts by selectively intercepting the solar radiation and by reducing the undesirable glare. A proper shading device can therefore significantly increase the thermal performance of a building by reducing its energy demand in different climate conditions. In order to identify the set of optimal shading devices that allow a low energy consumption of the dwelling while maintaining high levels of thermal and lighting comfort for the inhabitants we derive a multi-objective optimization methodology based on Harmony Search and Pareto front approaches. The results show that the multi-objective approach here proposed is an effective procedure in designing energy efficient shading devices when a large set of conflicting objectives characterizes the performance of the proposed solutions.
\end{abstract}

๑ 2016 Elsevier Ltd. All rights reserved.

\section{Introduction}

Amongst the several strategies for improving energy efficiency in Europe, buildings must be considered as the prime objective since they are responsible for about $40 \%$ of the energy consumption in Europe. The current EU building energy efficiency directives (Directives 2002/91/EC, 2010/31/UE, Nearly Zero Energy Building) impose new requirements in the renovation of existing residential buildings in order to transform them into nearly zero-energy buildings. In the renovation of existing buildings, intelligent strategies are essential to optimize building envelopes in order to minimize energy consumption while assuring thermal and lighting comfort for inhabitants $[1,2]$.

\footnotetext{
* Corresponding author.

E-mail addresses: marina.khoroshiltseva@unive.it (M. Khoroshiltseva), debora. slanzi@unive.it (D. Slanzi), irenpoli@unive.it (I. Poli).
}

Solar gains can greatly contribute to the building's thermal energy performance positively, in the sense of energy gains, or negatively, as energy demand. The incoming direct solar radiation may increase the solar comfort in the interior of building during the cold months and at the same time decrease the heating demand. But during summer the opposite effect occurs, since the solar radiation might cause overheating and thus increase the cooling demand. An efficient and cost effective way of avoiding the unwanted solar thermal gains in a building is the installation of shading devices. Shading devices can be categorized under interior and exterior shades [3].

The interior shades, though quite efficient with respect to glare reduction, are less likely to contribute to the thermal comfort of a building since they block the incoming radiation after it has already passed through the fenestration glazing. The exterior shades instead can block the direct solar radiation through the windows and reduce the heat transmission in the building, therefore can contribute to the thermal comfort regulation as well as to 
glare reduction. In this paper, we focus on exterior shades as they are more effective in reducing the amount of heat that enters a space when local climatic conditions and dweller's habits force a concentration on sun shading and the possibility of crossventilation of the building.

\subsection{Shading devices}

Indoor thermal and visual comfort vary with respect to direct sun exposition, day and night, summer and winter. Innovative façade daylight kits can effectively increase the indoor comfort and control the energy consumption [4,5]. A large number of studies have been conducted on the use and assessment of exterior and interior shading systems. Kim et al. conducted an experimental configuration and energy analysis simulation of several internal and external shading devices for apartment houses located in South Korea. They showed that experimental shading devices located outside provide a very good percentage of cooling energy saving when compared to internal devices [6]. A lighting and shading control strategy has been suggested by Yun et al. by analyzing several different parameterizations of an office building with respect to visual comfort and building energy demand [7]. Freewan examined the effect of several types of shading devices on controlling air temperature and improving illuminance level in offices located in hot climate regions showing that all shading devices improved the thermal and visual environment in the offices [8]. Several simulation studies have been performed by Huang et al. to evaluate the performance of different popular energy-efficient window designs in cooling-dominant climates showing that the comprehensive performance of overhangs is better than that of interior blinds [9]. Atzeri et al. compared the performance of outdoor and indoor shading devices concerning the thermal and visual comfort of an openspace office located in Rome showing that although the use of shades always improves the thermal comfort, the energy demand could increase as an effect of particular configuration of the building [10]. Five common shading configurations in five climate zones defined by ASHRAE have been compared by Babaizadeh et al. in order to provide guidance to decision about the design of shading systems in various types of facilities [11]. A very recent review on shading device types used different building types and different climatic regions has been proposed by Kirimtat et al. underlining the importance of simulation modeling to address the problem [12].

\subsection{Simulation and optimization of building shading devices}

The design of renovation kits, as shading devices, with the objective of optimizing the indoor comfort at low level of energy consumption, is generally a complex high dimensional multioptimization problem: it involves a large sets of interconnected variables that should be optimized with respect to several and conflicting objectives. A daylight device, in providing shade to the window, can in fact reduce a large proportion of the time of overheating of the building, improving the quality of indoor conditions for the occupants. However, sun shading can also produce negative effects which include a decrease in visual comfort and in winter solar gains, which in turn lead to an increase of energy consumption. The shape of these daylight devices should then optimize several objectives: reducing the overheating time of the building, providing high level of visual comfort, having small size area and finally requiring minimum level of energy consumption for heating, cooling and lighting. Also with respect to shading devices simulation and optimization, a huge number of studies have been developed. An exhaustive review of the studies of simulation-based optimization of passive solar design strategies has been carried out by Stevanović [13]. Among others, Zemella et al. proposed an evolutionary neural network design to derive the design of a typical façade module for an office building for both a single-objective and a multi-objective optimization process. They derived solutions based on the Pareto front achieving good results in both cases [14]. An approach based on genetic algorithm proposed by Manzan to optimize a fixed shading device of a south facing window in an office room demonstrated that this procedure can be a powerful tool [15]. A biogeography-based optimization algorithm was proposed by Hadidi to design and optimize plate fin exchangers with a relevant reduction of total cost, pressure drop and the heat transfer area of exchanger in comparison with other classical population-based procedures [16]. Blanco et al. developed a model to calculate the energy savings of the building due to the use of perforated sheet panels in different climate zones in Spain and optimized the estimated model to achieve the best configuration of façades for different zones and characteristics of the building [17]. We refer to Kirimtat et al. [12] for a complete review of simulation modeling for shading devices in buildings and to Nguyen et al. [18] for a review on simulation-based optimization methods applied to building performance analysis.

\subsection{Objectives}

In this paper, we confront the renovation of a residential building located in a modest area of Madrid with the objectives of reduction of energy consumption and enhancing the comfort level of inhabitants. The particular sunny climatic conditions of our case study lead to very high level of overheating of the indoor space producing high discomfort for the occupant and high levels of energy consumption for cooling and lighting [19]. In order to optimize the energy saving and to maintain the indoor thermal and lighting comfort of the inhabitants, we focus on the optimal design of static daylight devices, i.e. external shading devices, installed around the windows of the building. To address this multiobjective optimization problem we propose a stochastic approach consisting of a multi-objective combined methodology based on Harmony Search Algorithms [20,21] and the Pareto front [22,23] to identify a set of different optimal solutions for decision makers selection. This approach is named multi-objective Evolutionary Design for Optimization (m-EDO) and it was developed within the Design of Evolutionary Experiments based on models approach (DEEMs), a class of smart evolutionary procedure where evolution and information achieved by statistical models are combined to generate informative sequential populations of solutions [24-27]. The set of solutions that we achieved leads to a large increase of indoor comfort in terms of overheating with a low level of energy consumption also in comparison with the solutions with full or without shading device and other suggested optimal solutions provided by architects. These results suggest that with a low-cost and non invasive renovation intervention, a substantive amount of energy saving can be provided while assuring comfort levels for the inhabitants. The paper is organized as follows: in Section 2 we describe the structure of the particular shading device and the optimization strategy based on smart search algorithms and the Pareto front; in Section 3 we present the results of the optimization approach in terms of a set of optimal shading device shapes able to realize a large reduction of overheating discomfort with a low energy consumption; in Section 4 we present some conclusions.

\section{Methodology}

\subsection{The design of shading devices}

In deriving renovation strategies of existing buildings with the aim of increasing indoor thermal comfort and efficiency in energy 


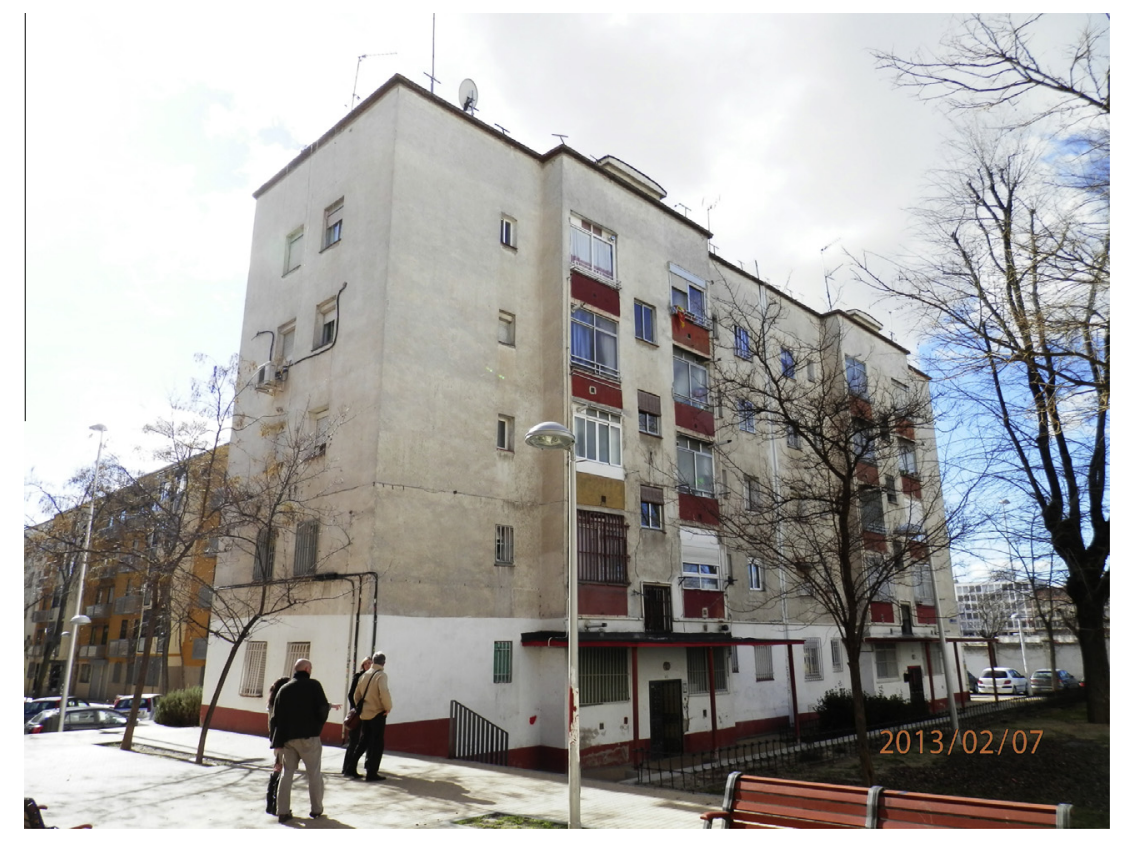

Fig. 1. Building of the Madrid case study before the renovation intervention. Source: http://www.inspirefp7.eu/about-inspire/downloadable-reports/.

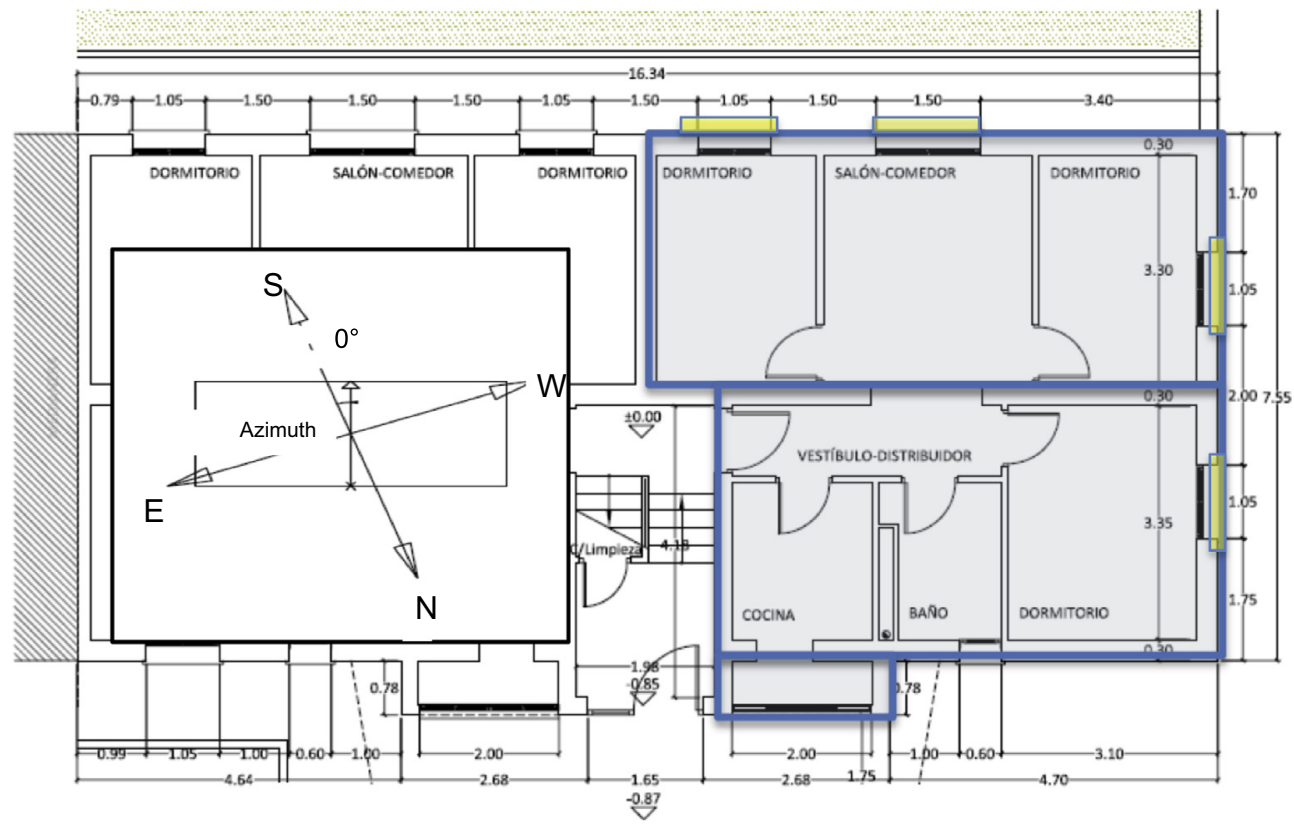

Fig. 2. Foorplan of the Madrid building, in blue the flat under study. (For interpretation of the references to color in this figure legend, the reader is referred to the web version of this article.) Source: http://www.inspirefp7.eu/about-inspire/downloadable-reports/.

consumption, an external shading device can play a key role $[28,13,29,12]$. In this study the optimization of two external devices is carried out on the apartment of a residential social housing built in the 1950s in Madrid (Spain). ${ }^{1}$ The building is located in San Cristobal de los Ángeles, a socially deprived urban area in the southern outskirts of Madrid, which was designated an "Area de Rehabilitacion Integrada" in 1999. The building has 20 dwellings (60 $\mathrm{m}^{2}$ gross area per dwelling) on 5 stories and is composed by 2

\footnotetext{
${ }^{1}$ This case study is considered in the EU project INSPIRE - Development of systematic packages for deep energy renovation of residential and tertiar buildings including envelope and systems.
}

linear blocks linked through the staircase. A photo of the building before the renovation intervention is presented in Fig. 1. The flat, to be considered on the last floor of the building, has an orientation towards the South-West. In Fig. 2 we present the floorpan of the considered building and we report in blue the particular flat of the optimization. The idea of intelligently designing static external devices allows a minimized overheating and a minimized heating and artificial lighting demand by blocking or reducing direct irradiation at specific times of the year and allowing cross ventilation of the flat. Furthermore the manufacturing, installation and maintenance costs are small compared to other devices, allowing a feasible solution for this particular poor area of Madrid. The details of building 
construction, including structure and materials of wall, ceiling and windows are defined according to the specific building design and are shown in Table 1.

For this study, we consider the simultaneous design of static external shading devices surrounding four windows of the flat, with west and south orientation, as highlighted in yellow in Fig. 2, assuming that windows at the same orientation are characterized by similar sun exposition. Within this assumption, we consider a window for each of the two orientations (west and south) to which provide a daylight device composed by 6 elements of rectangular shape, namely fins, each of which with length (in meter) defined in the discrete interval $[0.05,0.70]$ with a step of 0.05 (14 possible levels). Therefore, the setting of the shading design can be described by a set of variables $X_{i}, i=1, \ldots, 12$, where each variable $X_{i}$ assumes values in the set $\{0.05,0.10, \ldots, 0.65,0.70\}$. A solution, i.e. a candidate shading device, is presented by the set of variable values

$\omega_{\mathbf{k}}=\left[x_{1 j}, x_{2 j}, \ldots, x_{12 j}\right] \quad j=1, \ldots, 14$, where $x_{i j} \in\{0.05,0.10, \ldots, 0.65,0.70\}$, with $i=1, \ldots, 12$ and $j=1, \ldots, 14$. Within this setting, $\omega_{\mathbf{k}}$ represents the $k$ th design point of the combinatorial search space $\Omega$, that consists of $14^{12}$ points. The search space $\Omega$ then consists of all the possible combinations of the 12 shading elements with length ranging between 0.05 and $0.7 \mathrm{~m}$. An example of a possible solution, i.e. possible shading device configuration for a window, is presented in Fig. 3. In this extremely large search space, we developed a stochastic evolutionary procedure to find the set of optimal combinations of shading elements with respect to several response indicators representing correlated and conflicting objectives such as overheating and energy demand for heating and lighting.

\subsection{Response indicators}

To evaluate the proposed shading solutions, we select the response indicators listed below, which we will consider as the objective variables for the optimization problem. The values of

Table 1

Properties of building components.

\begin{tabular}{|c|c|c|c|c|c|c|c|}
\hline $\begin{array}{l}\text { Building } \\
\text { components }\end{array}$ & Material & $\begin{array}{l}\text { Thickness } \\
{[\mathrm{m}]}\end{array}$ & $\begin{array}{l}\text { Conductivity [W/ } \\
\mathrm{mK}]\end{array}$ & $\begin{array}{l}\text { Density }[\mathrm{kg} / \\
\left.\mathrm{m}^{3}\right]\end{array}$ & $\begin{array}{l}\text { Specific heat [J/ } \\
\mathrm{kg} \mathrm{K}]\end{array}$ & $\begin{array}{l}\text { Thermal } \\
\text { absorptance }\end{array}$ & $\begin{array}{l}\text { Solar } \\
\text { absorptance }\end{array}$ \\
\hline \multicolumn{8}{|l|}{ EXT WALL } \\
\hline & Concrete slab & 0.28 & 1.13 & 2000.00 & 1000.00 & 0.90 & 0.50 \\
\hline & Air gap & 0.03 & 0.17 & 1.20 & 1000.00 & 0.90 & 0.50 \\
\hline & $\begin{array}{l}\text { Lime cement } \\
\text { mortal }\end{array}$ & 0.04 & 0.72 & 1920.00 & 840.00 & 0.90 & 0.50 \\
\hline & Plasterboard & 0.01 & 0.40 & 1000.00 & 1000.00 & 0.90 & 0.50 \\
\hline \multicolumn{8}{|l|}{ CEILING } \\
\hline & $\begin{array}{l}\text { Lime cement } \\
\text { mortal }\end{array}$ & 0.04 & 0.88 & 2800.00 & 896.00 & 0.90 & 0.50 \\
\hline & Asphalt tile & 0.02 & 1.30 & 2200.00 & 712.00 & 0.90 & 0.50 \\
\hline & Concrete slab & 0.20 & 1.13 & 2000.00 & 1000.00 & 0.90 & 0.50 \\
\hline Windows & U-Factor & \multicolumn{2}{|c|}{ Solar heat gain coefficient } & \multicolumn{4}{|c|}{ Visible transmittance } \\
\hline WINDOW 1 & 6.11 & 0.81 & & 0.81 & & & \\
\hline WINDOW 2 & 2.7 & 0.70 & & 0.70 & & & \\
\hline
\end{tabular}
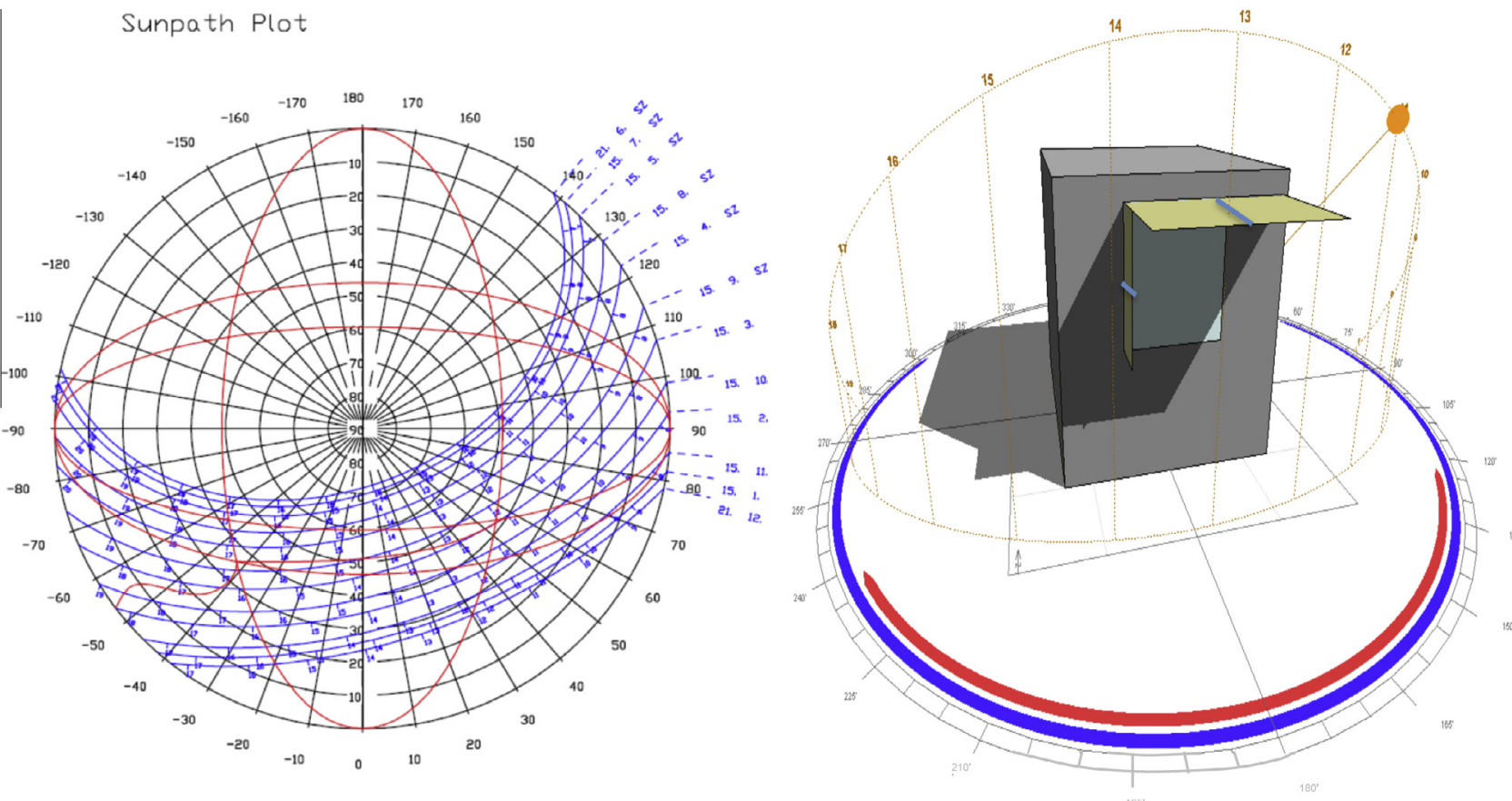

Fig. 3. An example of a static shading device solution. Source: http://www.inspirefp7.eu/about-inspire/downloadable-reports/. 
Table 2

Input parameters used in the EnergyPlus simulation.

\begin{tabular}{|c|c|}
\hline Location & Madrid \\
\hline $\begin{array}{l}\text { Latitude, Longitude, } \\
\text { Height }\end{array}$ & $40.45,-3.55,1.0,582.0$ \\
\hline Orientation & South Southwest \\
\hline Flat dimension & $57 \mathrm{~m}^{2}$ \\
\hline $\begin{array}{l}\text { Glazing-to-façade ratio } \\
\text { SSE }\end{array}$ & $14 \%$ \\
\hline $\begin{array}{l}\text { Glazing-to-façade ratio } \\
\text { NNW }\end{array}$ & $18 \%$ \\
\hline Infiltration/Ventilation & $\begin{array}{l}0.45 \mathrm{ACH} \\
1: 00: 00-8: 00 \text { and } 19: 00-24: 00 \\
0.5: 8: 00-19.00 \\
\text { Weekends } 1: 24 \mathrm{~h}\end{array}$ \\
\hline Equipment heat gain & $\begin{array}{l}\text { Light } 2: \mathrm{W} / \mathrm{m}^{2} \\
0: 00: 00-6: 00 \\
1: 6: 00-24: 00 \\
\text { Equipment specific profile resulting in average } \\
11.67 \mathrm{~W} / \mathrm{m}^{2}\end{array}$ \\
\hline Occupation & $\begin{array}{l}0.052 \text { people } / \mathrm{m}^{2} \\
\text { 1: } 00: 00-8: 00 \text { and } 19: 00-24: 00 \\
0.5: 8: 00-19: 00\end{array}$ \\
\hline $\begin{array}{l}\text { People radiant fraction } \\
\text { Activity level } \\
\text { Illuminance sensor }\end{array}$ & $\begin{array}{l}0.3 \\
120 \mathrm{~W} / \text { person } \\
0.8 \mathrm{~m} \text {, position in SSE room in flat }\end{array}$ \\
\hline $\begin{array}{l}\text { Heating thermostat set- } \\
\text { point }\end{array}$ & $\begin{array}{l}18^{\circ} \mathrm{C}: 0: 00-6: 00 \\
20^{\circ} \mathrm{C}: 6: 00-18: 00 \\
18^{\circ} \mathrm{C}: 18: 00-24: 00 \\
18^{\circ} \mathrm{C}: \text { Weekends }\end{array}$ \\
\hline $\begin{array}{l}\text { Cooling thermostat set- } \\
\text { point }\end{array}$ & Not active \\
\hline
\end{tabular}

response variables are achieved by simulation with the EnergyPlus software. The specific simulation input parameters of this case study are presented in Table 2 . The optimization process that we address involves the simultaneous minimization of the response variables: Overheating, Change in energy demand and Area of devices, as described in the following.

\subsubsection{Overheating}

Overheating is defined as the proportion of hours during the year for which the room exceeds the default temperature of $26{ }^{\circ} \mathrm{C}$. We consider this indicator as the response variable $Y_{1}$ to minimize in the optimization process. $Y_{1}$ is therefore defined as:

$Y_{1}=f_{1}(\omega \mid \mathbf{z}, \mathbf{u})=\frac{\sum_{t=1}^{D} o v_{t}(\omega)}{D}$

where $o v_{t}(\omega)$ is an Indicator function assuming value equal to 1 when the mean hourly indoor temperature at time $t$ is greater than $26{ }^{\circ} \mathrm{C}$, and 0 otherwise; $D$ represent the total number of hours $t$ in the year; $\mathbf{z}$ and $\mathbf{u}$ are the set of weather conditions and building input parameters respectively.

\subsubsection{Change in energy demand}

Change in annual energy demand is defined as sum of differences between initial and actual energy demand for heating and lightning, measured in $\mathrm{kWh}$. We consider this indicator as the response variable $Y_{2}$ to minimize in the optimization process. $Y_{2}$ is defined as:

$Y_{2}=f_{2}(\omega \mid \mathbf{z}, \mathbf{u})=\left(Q_{H \omega}-Q_{H 0}\right)+\left(Q_{L \omega}-Q_{L 0}\right)$,

where $Q_{H \omega}=\sum_{t=1}^{D} q_{H t}$ and $Q_{L \omega}=\sum_{t=1}^{D} q_{L t}$ are energy demand values for heating and lighting required by the $\omega$ solution, calculated as the sum of hourly energy demand for respectively heating at time $t$, i.e. $q_{H t}$, and for lighting at time $t$. i.e. $q_{L t} ; D$ represents the total number of hours $t$ in the year; $Q_{H 0}$ and $Q_{L 0}$ are initial energy demand for heating and lighting without any daylight device; $\mathbf{z}$ and $\mathbf{u}$ are the set of weather conditions and building input parameters.

\subsubsection{Area of the static daylight devices}

The Area of shading device is the sum of the areas of all elements of devices (fins and overhangs) surrounding the windows. Each element has a rectangular shape where the height is represented by the design variable in the candidate solution $\omega$, while the base is defined by the size of the windows and is fixed equal to $0.525 \mathrm{~m}$ and $0.7595 \mathrm{~m}$ for west and south overhangs respectively and $0.6 \mathrm{~m}$ for all lateral fins. We consider this indicator as the response variable $Y_{3}=f_{3}(\omega)$ to be minimized in the optimization process.

\subsubsection{Shape acceptance}

Shape acceptance is a function that represents the visual acceptance architectural feasibility of the candidate solution. Shape of the device is considered as acceptable if satisfies the following constraints:

1. Bottom elements are not longer than top elements.

2. The difference in lengths of the top fins is less than $0.1 \mathrm{~m}$.

We define this indicator as the response variable $Y_{4}=f_{4}(\omega)$ to be minimized in the optimization process. A solution with $Y_{4}=0$ indicates that its shape is acceptable, i.e. all the constrains are satisfied, while a solution producing a $Y_{4}$ value greater than 0 has violated the visual acceptance architectural feasibility. The variable $Y_{4}$ therefore represents a measure of the violation of the constraints (sum of all the differences between the observed lengths and the defined shape limits).

\subsection{The multi-objective Evolutionary Design for Optimization ( $m$ - EDO)}

Optimization techniques for building design are emerging as an interesting tool for designing energy efficient building in accordance with several objectives [30]. To address an optimization problem several evolutionary procedures involving different search algorithms, such as model-based Genetic Algorithms $[31,15,23]$, Particle Swarm Optimization [32,33], and Harmony Search [34,21], can be considered. The evolutionary approach, based on a set of metaheuristics, is able to process just a small set of candidate solutions, instead of all solutions in the search space, achieving very good results in converging to the real optimal values. Among the several approaches, comparative simulation studies showed the very good performance of evolutionary algorithms based on Harmony search [35-37]. The Harmony search algorithm was firstly developed by Geem et al. [35] in analogy with the music improvisation process of musicians adjusting the pitches of their instruments to obtain the best harmony. Briefly, the pitches of instruments correspond to the values of the design variables, and the obtained harmony corresponds to the objective response to optimize. The music improvisation is the process of search for the better harmony, and in each step of the improvisation process, i.e. the optimization, each musician can try various combinations of pitches following three specific rules:

- playing any one pitch from memory, which means choosing any design variable value from the so called Harmony Memory representing the past; 
- playing an adjacent pitch to one pitch from the memory, which means choosing an adjacent variable value from the Harmony Memory adjusting the pitch;

- playing a random pitch from the possible range, which means choosing a random value from the possible variable value range.

These three rules in the algorithm are mainly controlled by two essential probabilistic operators: Harmony Search Considering Rate (HMCR) and Pitch Adjusting Rate (PAR). The HMCR is defined as the probability of selecting a component from the memory or being generating it randomly; PAR determines the probability of choosing an adjacent variable value (corresponding, in some ways, to the probability of a candidate from the Harmony Memory to be mutated). When a new candidate solution has been generated, if this new solution is better than the worst solution in the Harmony Memory then replace the worst solution by the new one. After the maximum number of iterations has been performed, the best solutions from the Harmony Memory are returned. The solution quality is enhanced iteration by iteration, till the search process converges to the best solution. More details about the algorithm can be found in $[36,37]$.

For the multi-objective optimization, instead of proceeding via the simple linear combination of single optimal solutions, we include the computation of the Pareto front values [22,23]. The Pareto front is defined as the set of all non-dominated solutions, where a solution $\omega_{\mathbf{k}}$ is said to be non-dominated by solution $\omega_{\mathbf{j}}$ if both the following conditions are satisfied: the response value of solution $\omega_{\mathbf{k}}$ is not worse than the response value of solution $\omega_{\mathbf{j}}$ in all the objectives; the response value of $\omega_{\mathbf{k}}$ is strictly better than $\omega_{\mathbf{j}}$ in at least one response. The combination of evolutionary optimization based on Harmony Search procedure and Pareto Front approach leads to the definition of the multi-objective Evolutionary Design for Optimization (m-EDO) as represented in Fig. 4.

Algorithm 1. multi-objective Evolutionary Design for Optimization (m-EDO)

Require: Building parameters, EnergyPlus input data

Ensure: The optimal shading devices via m-EDO design

1: initialise $n_{q}$, Ngen, HMCR, PAR

2: $D_{1}=\left[\omega_{\mathbf{1}} \omega_{\mathbf{2}} \cdots \omega_{\mathbf{n}_{1}}\right] \leftarrow$ First random Harmony Memory

(HM) of $n_{1}$ shading solutions

3: evaluate $\mathbf{y}_{1,1}, \mathbf{y}_{2,1}, \mathbf{y}_{3,1}, \mathbf{y}_{4,1} \forall D_{1}$

4: $D_{1}^{\star} \leftarrow \operatorname{NonDomSet}\left(D_{1}\right)$ archive of Pareto non-dominated solutions

5: for $q$ in 2: Ngen do

6: improvise new Harmony Memory $\mathrm{HM}_{q}$ using the basic rules based on HMCR and PAR

7: $\quad D_{q}=\left[\omega_{\mathbf{1}} \omega_{\mathbf{2}} \cdots \omega_{\mathbf{n}_{\mathbf{q}}}\right] \leftarrow \mathrm{HM}_{q}$ new $n_{q}$ shading solutions

8: $\quad$ evaluate $\mathbf{y}_{1, q}, \mathbf{y}_{2, q}, \mathbf{y}_{3, q}, \mathbf{y}_{4, q} \forall D_{q}$

9: update archive of Pareto non-dominated solutions

$D_{q}^{\star} \leftarrow \operatorname{NonDomSet}\left(\bigcup_{j=1}^{q-1} D_{j}^{\star} \cup D_{q}\right)$

10: end for

11: m-EDO design $\leftarrow\left[D_{N_{g e n}}^{\star}, \mathbf{y}_{1, N_{g e n}}^{\star}, \mathbf{y}_{2, N_{\text {gen }}}^{\star}, \mathbf{y}_{3, N_{\text {gen }}}^{\star}\right]$

In this research we developed m-EDO to design the set of optimal solutions representing the static shading devices within the setting defined for our case study, i.e. building parameters and EnergyPlus input data as presented in Section 2.1. The pseudocode of the procedure can be found in Algorithm 1. In particular $\mathrm{m}$-EDO is run for $N_{\text {gen }}=50$ generations where each generation consists of $n_{q}=30$ possibile solutions producing a total number of shading candidate solution equals 1500 , representing just a very small number of possible configurations with respect to the whole search space. The value of the probabilistic operators of the Harmony Search procedure are fixed equal to $\mathrm{HMCR}=0.9$ and $\mathrm{PAR}=0.8$, i.e. the standard parameters used in most of the applications reported in the literature.

\section{Results}

In the developed optimization procedure we select and evaluate a very small set of candidate solutions with respect to the whole experimental search space, 1500 solutions out of $14^{12}$, representing the most informative solutions for the optimization objectives.

In Table 3 we present the Pearson correlation coefficients calculated for each pair of response variables in the set of generated solutions. We can see that correlations are very high for almost all pairs of response variables with several negative signs, specifically for $Y_{1}$ with $Y_{2}$ and $Y_{1}$ with $Y_{3}$, indicating the conflictive nature of these response variables. It is worth mentioning that energy demand refers only to energy for heating and lighting since aircooling was not considered for the renovation intervention. Overheating in summer can therefore be reduced by the installation of a shading device but this leads to an increasing demand for heating and artificial lighting during winter periods as the shading device prevents the solar radiation and its positive effect when entering into the flat. This produces a very high inverse correlation between $Y_{1}$, representing overheating, and $Y_{2}$, representing change for energy demand. Moreover as the effect of solar radiation on the flat depends on the area of the shading device, it is pretty clear that a small area of shading device causes a very high value of overheating in summer; on the other hand a very big area of shading device prevents overheating but increases energy demand. This produces a very high inverse correlation between $Y_{1}$ and $Y_{3}$ representing the area of the shading devices and a positive correlation between $Y_{2}$ and $Y_{3}$. Shape acceptance $Y_{4}$ doesn't have any significative correlation with the other response variables.

Fig. 5 shows all the 1500 solutions achieved by m-EDO approach, and the 75 Pareto solutions (red stars), identified by the simultaneous minimization of all the responses variables. As $Y_{4}$ has no significant correlation with other response variables, we represent the behavior of the achieved solutions only for $Y_{1}, Y_{2}$ and $Y_{3}$. The conflicting performance of the solutions is highlighted by the form of the Pareto front covering values of overheating and change in energy demand in a wide range of possibilities. All the optimal solutions in the Pareto Front are in fact very informative for designing static daylight device; in this set of optimal solutions designers and architects can identify the most appropriate shading device design for any defined target assuring that the selected solution is in the set of the best achieved solutions with respect to the optimization objectives.

The main summary statistics of the Pareto front solutions are presented in Table 4. Focusing on the statistics of the distribution for $Y_{1}$ representing overheating, we can notice that most of the solutions achieve a value between 0.179 and 0.184 representing the interquartile range, with a Gaussian distribution centered in the mean value of 0.182 , showing that the proportion of hours during the year for which the flat exceeds the default temperature of $26^{\circ} \mathrm{C}$ is around $18 \%$. Gaussian distributions can also be adopted for describing the behavior of $Y_{2}$ representing change in energy demand, and $Y_{3}$ representing area. The statistics of the distribution of $Y_{3}$ show how most of the values ranges from $5.005 \mathrm{~m}^{2}$ to $5.765 \mathrm{~m}^{2}$ but with minimum and maximum values very far with respect to the first and third quartiles indicating long tails of the distribution. This means that several optimized shading devices present very small or very big areas. Having observed the conflicting behavior of overheating with the area of the shading device, we 


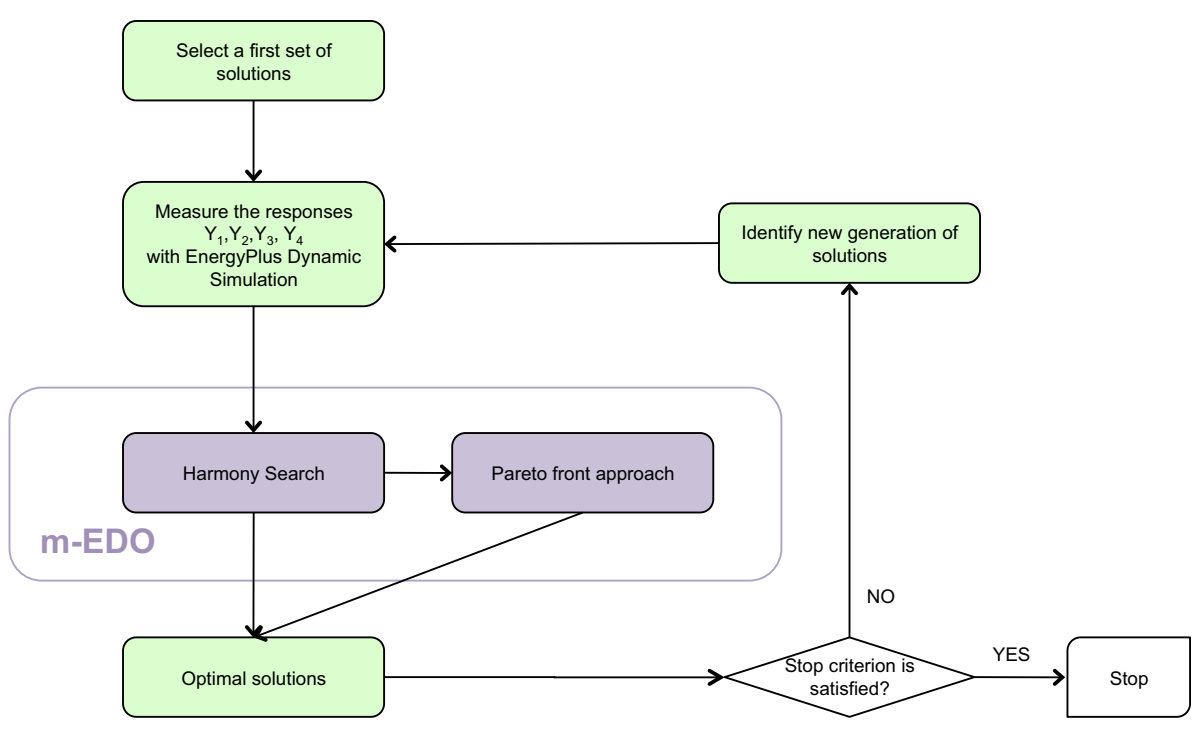

Fig. 4. The optimization procedure.

Table 3

Pearson correlation coefficient between response variables.

\begin{tabular}{rrrrr}
\hline & $Y_{1}$ & \multicolumn{1}{c}{$Y_{2}$} & \multicolumn{1}{c}{$Y_{3}$} & \multicolumn{1}{c}{$Y_{4}$} \\
\hline$Y_{1}$ & 1.000 & -0.865 & -0.806 & 0.319 \\
$Y_{2}$ & -0.865 & 1.000 & 0.747 & -0.043 \\
$Y_{3}$ & -0.806 & 0.747 & 1.000 & -0.001 \\
$Y_{4}$ & 0.319 & -0.043 & -0.001 & 1.000 \\
\hline
\end{tabular}

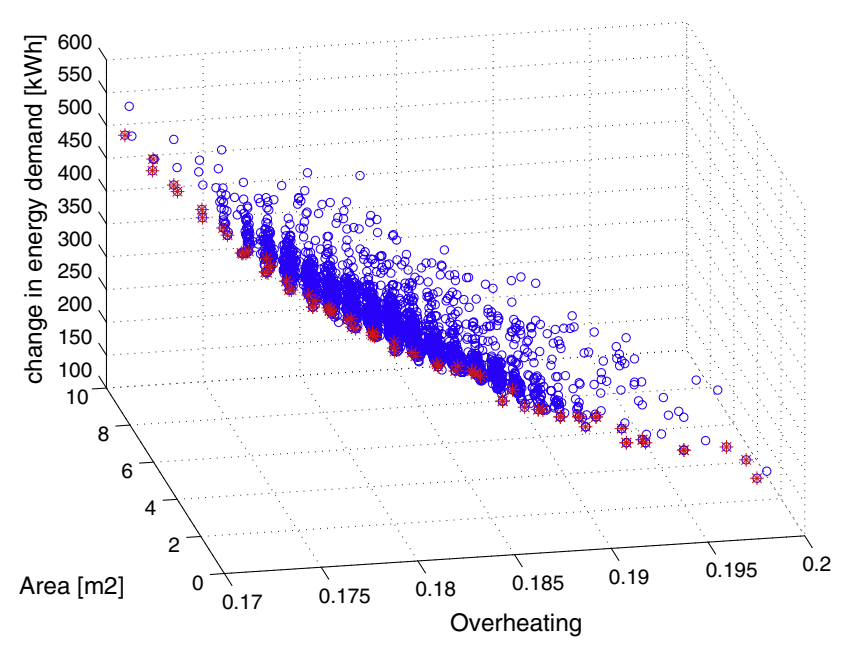

Fig. 5. Distribution of the solutions achieved by m-EDO. The optimal solutions in the Pareto front are represented by red stars. (For interpretation of the references to color in this figure legend, the reader is referred to the web version of this article.)

expect to select solutions with values of area exceeding the third quartile of its distribution in order to prevent overheating. From the statistics of the distribution for $Y_{4}$ shape acceptance, a skew distribution toward very low values is suggested as m-EDO prefers solutions within the constraints assumed in the definition of the response.

Moreover for the Pareto front solutions, the conflicting effect between overheating and change in energy demand is shown in Fig. 6. In this figure, red $^{2}$ stars represent the value of $Y_{1}=$ overheat-

\footnotetext{
${ }^{2}$ For interpretation of color in Fig. 6, the reader is referred to the web version of this article.
}

ing and green circles represents the value of $Y_{2}=$ change in energy demand for all the 75 solutions of the Pareto Front. This shows that the best solution from the overheating point of view, $Y_{1}=0.170$, corresponds to the solution with value of change in energy demand very close to the maximum, $Y_{2}=545.100$. Then incrementing the value of overheating will decrease the change in energy demand.

In order to select a smaller set of optimal solutions, we focused only on the Pareto front solutions achieving particular levels of overheating and impacts on energy demand. This set of solutions was therefore selected considering the following criteria: solutions that have a large effect on the comfort (overheating $<0.180$ ) and satisfy the shape acceptance that we proposed, i.e. $Y_{4}=0$. This choice is mainly motivated by the climatic conditions of our case study, as hot summers have very high discomfort impacts on inhabitants. Fig. 7 shows all the identified Pareto front solutions where the 11 shading devices with the lowest levels of overheating and shape acceptance are represented by black points.

For these selected solutions we present in Table 5 the optimized values for the design variables, i.e. the size of each element (fin) of the devices for South and West orientation, and the corresponding values of the responses (here $Y_{4}$ is not reported as its value is equal to 0 for all the selected shading solutions). We notice that the size of the fins are generally smaller for south than for west orientation. In particular, the results show that for the top fins (overhangs) and the lateral left side fins, i.e. fins oriented towards the south, the lengths are almost always set equal to $0.70 \mathrm{~m}$, representing the possible maximum value for the design variables. This indicates the greater need of a shading device for the west window with respect to the south window orientation.

To evaluate the range of variation for the response values, we derive Overheating, Energy demand for heating and lighting and the corresponding Change in energy demand for the set of selected optimal solutions and for the extreme shapes of shading device, i.e. the solution with maximum area and the solution without shading device. These extreme values of optimization are reported in Table 6.

Moreover, in Table 6 we derive the percentage variation of Overheating $\Delta_{Y_{1}}$ and the percentage variation of Change in energy demand $\Delta_{Y_{2}}$ with respect to the solution without shading device, which is considered as the initial point of the building renovation process. In particular $\Delta_{Y_{1}}$ is calculated as $\Delta_{Y_{1}}=\left(Y_{1}(\omega)-Y_{1}(0)\right) / Y_{1}(0)$ and $\Delta_{Y_{2}}=Y_{2}(\omega) / Y_{2}(0)$, where $Y_{1}(0)$ 
Table 4

Summary statistics of the Pareto front solutions.

\begin{tabular}{|c|c|c|c|c|c|c|c|}
\hline & Min & 1Q & Mean & Median & $3 Q$ & Max & Sd \\
\hline Overheating $\left(Y_{1}\right)$ & 0.170 & 0.179 & 0.179 & 0.182 & 0.184 & 0.199 & 0.004 \\
\hline Change in energy demand $\left(Y_{2}\right)$ & 121.600 & 270.500 & 314.074 & 309.700 & 352.725 & 584.400 & 62.302 \\
\hline Area $\left(Y_{3}\right)$ & 1.576 & 5.005 & 5.373 & 5.395 & 5.765 & 8.425 & 0.644 \\
\hline Shape acceptance $\left(Y_{4}\right)$ & 0.000 & 0.250 & 0.522 & 0.450 & 0.700 & 2.550 & 0.366 \\
\hline
\end{tabular}

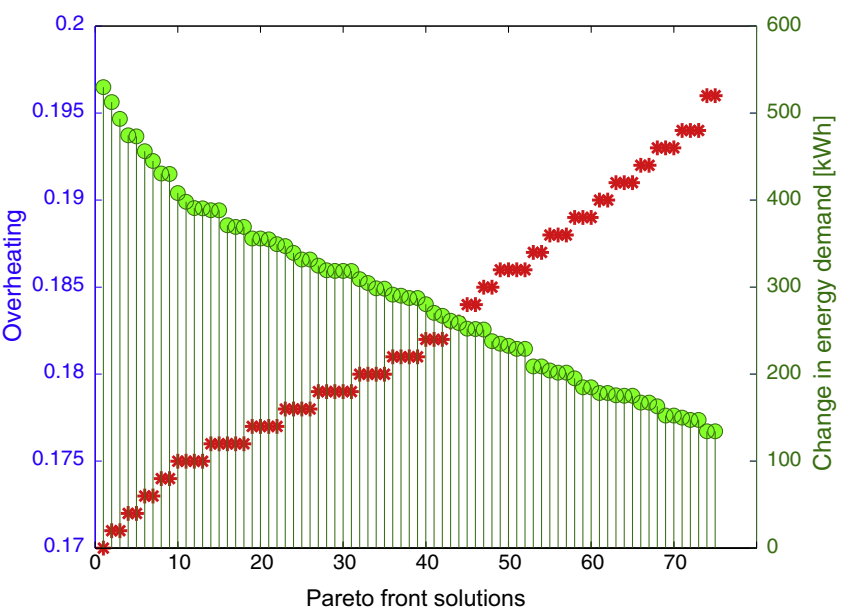

Fig. 6. Overheating and change in energy demand for the 75 Pareto front solutions.

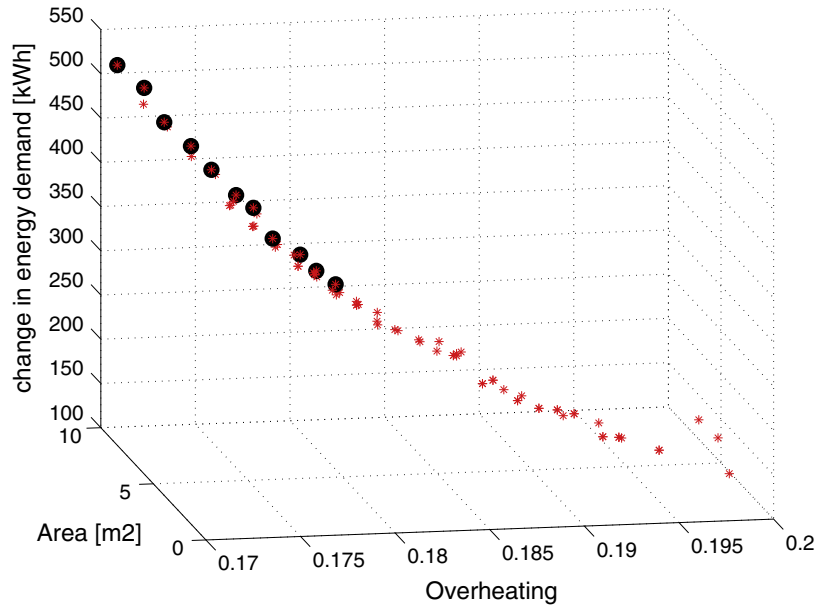

Fig. 7. Pareto solutions with lowest levels of overheating $(<0.180)$ and shape acceptance equal to 0 (black points). and $Y_{2}(0)$ are the initial levels of overheating and energy demand (solution with no shading device) and $Y_{1}(\omega)$ and $Y_{2}(\omega)$ represent the values of overheating and change in energy demand for the solution $\omega$.

The best solution achieved by the m-EDO procedure in term of the minimum thermal discomfort is the solution with overheating level of $17 \%$ (solution 1 in Table 6). This level is very close to the extreme value (minimum possible level of overheating obtained by maximum area of the shading device) but it is worth noting that this best solution requires a change in energy demand which is around $20 \%$ less than the solution with maximum area (change of $545.10 \mathrm{~kW} \mathrm{~h}$ and $685.20 \mathrm{~kW}$ h respectively).

A graphical representation of this selected best solution is presented in Fig. 8. Moreover, comparison between this best solution and the initial condition before the renovation of the building, i.e. building with no shading devices, can be realized also using several indicators showing the different effect on thermal comfort and energy demand, as reported in Table 7.

From this table, we can see that the shading device can strongly affect the thermal comfort of the building by decreasing the overheating ratio from 0.21 to 0.17 . Moreover in summer, when the hot condition of Madrid usually warms up the temperature of the indoor spaces, we can notice that the overheating reduction goes from 0.80 to 0.69 , highlighting the very good performance of the proposed solution. To show how the temperature inside the flat is affected by the impact of the shading device, we report in Fig. 9 the simulated summer seasonal trend of temperature for the situation without shading device (no renovation of the building) and for the situation in which the best shading device in terms of overheating is installed surround the windows of the flat. From this figure we can see how external shading devices can control the amount of sunlight and reduce the glare of discomfort for the inhabitants as well as the temperature inside the room.

\section{Conclusion}

In this paper we proposed a multi-objective evolutionary design approach for the optimization (m-EDO) of shading devices which are part of the renovation kits of an existing residential building in Madrid. Specifically, we developed a combined approach where the search process has been tackled by means of Harmony Search

Table 5

Optimal selected solutions according to Pareto front: shape size of the window fins for south and west orientation and corresponding response values.

\begin{tabular}{|c|c|c|c|c|c|c|c|c|c|c|c|c|c|c|c|}
\hline & \multicolumn{6}{|c|}{ South window } & \multicolumn{6}{|c|}{ West window } & \multirow{2}{*}{$\begin{array}{l}\text { Overheating } \\
Y_{1}\end{array}$} & \multirow{2}{*}{$\begin{array}{l}\text { Change in energy } \\
\text { demand [kW h] } \\
Y_{2}\end{array}$} & \multirow{2}{*}{$\begin{array}{l}\text { Area }\left[\mathrm{m}^{2}\right] \\
Y_{3}\end{array}$} \\
\hline & $X_{1}$ & $X_{2}$ & $X_{3}$ & $X_{4}$ & $X_{5}$ & $X_{6}$ & $X_{7}$ & $X_{8}$ & $X_{9}$ & $X_{10}$ & $X_{11}$ & $X_{12}$ & & & \\
\hline Solution 1 & 0.45 & 0.60 & 0.70 & 0.60 & 0.15 & 0.40 & 0.50 & 0.50 & 0.70 & 0.70 & 0.60 & 0.70 & 0.170 & 545.10 & 7.84 \\
\hline Solution 2 & 0.35 & 0.60 & 0.65 & 0.55 & 0.25 & 0.25 & 0.50 & 0.70 & 0.70 & 0.70 & 0.50 & 0.70 & 0.171 & 512.70 & 7.68 \\
\hline Solution 3 & 0.40 & 0.60 & 0.65 & 0.55 & 0.10 & 0.10 & 0.65 & 0.65 & 0.70 & 0.70 & 0.55 & 0.70 & 0.172 & 474.60 & 7.56 \\
\hline Solution 4 & 0.45 & 0.55 & 0.65 & 0.60 & 0.05 & 0.05 & 0.15 & 0.60 & 0.65 & 0.70 & 0.60 & 0.70 & 0.173 & 456.30 & 6.82 \\
\hline Solution 5 & 0.40 & 0.60 & 0.60 & 0.50 & 0.05 & 0.05 & 0.15 & 0.60 & 0.70 & 0.70 & 0.55 & 0.70 & 0.174 & 430.60 & 6.67 \\
\hline Solution 6 & 0.15 & 0.40 & 0.55 & 0.50 & 0.10 & 0.15 & 0.35 & 0.40 & 0.70 & 0.70 & 0.55 & 0.60 & 0.175 & 408.10 & 6.14 \\
\hline Solution 7 & 0.35 & 0.45 & 0.45 & 0.40 & 0.10 & 0.15 & 0.35 & 0.45 & 0.65 & 0.70 & 0.60 & 0.60 & 0.176 & 390.90 & 6.28 \\
\hline Solution 8 & 0.35 & 0.40 & 0.45 & 0.35 & 0.05 & 0.05 & 0.40 & 0.50 & 0.70 & 0.70 & 0.55 & 0.70 & 0.177 & 355.90 & 6.24 \\
\hline Solution 9 & 0.10 & 0.35 & 0.45 & 0.50 & 0.05 & 0.05 & 0.40 & 0.40 & 0.70 & 0.70 & 0.35 & 0.50 & 0.178 & 347.20 & 5.43 \\
\hline Solution 10 & 0.15 & 0.40 & 0.40 & 0.30 & 0.05 & 0.10 & 0.30 & 0.30 & 0.65 & 0.70 & 0.70 & 0.70 & 0.179 & 324.70 & 5.71 \\
\hline Solution 11 & 0.30 & 0.30 & 0.30 & 0.30 & 0.10 & 0.10 & 0.35 & 0.40 & 0.60 & 0.70 & 0.55 & 0.70 & 0.180 & 309.20 & 5.66 \\
\hline
\end{tabular}


Table 6

Selected solutions, extreme solutions and their impacts on overheating and change in energy demand (values and \%).

\begin{tabular}{|c|c|c|c|c|c|c|}
\hline Solutions & Area $\left[\mathrm{m}^{2}\right]$ & Overheating & Energy demand [kW h] & $\begin{array}{l}\text { Change in energy } \\
\text { demand [kW h] }\end{array}$ & $\begin{array}{l}\Delta_{Y_{1}} \text { Percentage variation } \\
\text { of overheating [\%] }\end{array}$ & $\begin{array}{l}\Delta_{Y_{2}} \text { Percentage variation } \\
\text { of change in energy demand [\%] }\end{array}$ \\
\hline Without SD & 0.00 & 0.213 & 3422.9 & 0.00 & 0.0 & 0.0 \\
\hline Solution 1 & 7.84 & 0.170 & 3968.0 & 545.10 & -20.19 & 15.93 \\
\hline Solution 2 & 7.68 & 0.171 & 3935.6 & 512.70 & -19.72 & 14.98 \\
\hline Solution 3 & 7.56 & 0.172 & 3897.5 & 474.60 & -19.25 & 13.87 \\
\hline Solution 4 & 6.82 & 0.173 & 3879.2 & 456.30 & -18.78 & 13.33 \\
\hline Solution 5 & 6.67 & 0.174 & 3853.5 & 430.60 & -18.31 & 12.58 \\
\hline Solution 6 & 6.14 & 0.175 & 3831.0 & 408.10 & -17.84 & 11.92 \\
\hline Solution 7 & 6.28 & 0.176 & 3813.8 & 390.90 & -17.37 & 11.42 \\
\hline Solution 8 & 6.24 & 0.177 & 3778.8 & 355.90 & -16.90 & 10.40 \\
\hline Solution 9 & 5.43 & 0.178 & 3770.1 & 347.20 & -16.43 & 10.14 \\
\hline Solution 10 & 5.71 & 0.179 & 3747.6 & 324.70 & -15.96 & 9.49 \\
\hline Solution 11 & 5.66 & 0.180 & 3732.1 & 309.20 & -15.49 & 9.03 \\
\hline Max area SD & 9.98 & 0.169 & 4108.1 & 658.20 & -20.66 & 20.02 \\
\hline
\end{tabular}

Table 7

Analysis of the best solution in comparison with initial condition before the renovation of the building (no shading devices).

\begin{tabular}{lccc}
\hline & No renovation & Best solution $s_{1}$ & Difference [\%] \\
\hline COMFORT & & & -13.11 \\
Summer overheating [\%] for period & 0.80 & 0.69 & -20.19 \\
Annual overheating [\%] & 0.21 & -3.30 \\
Mean temperature in summer period $\left[{ }^{\circ} \mathrm{C}\right]$ & 28 & 27 & -2.10 \\
Maximum temperature [ ${ }^{\circ} \mathrm{C}$ ] & 34.80 & 34.00 & 17.80 \\
ENERGY DEMAND & & & 5.90 \\
Annual energy demand for heating [kW h] & 2875.30 & 3388.01 & 15.93 \\
Annual energy demand for lightning [kW h] & 547.60 & 580.03 & -13.11 \\
Annual energy demand (heating + lightning) [kW h] & 3422.90 & 3968.04 & 3.40 \\
THERMAL DISCOMFORT & & & 1650.00 \\
$\mathrm{~N}$ of summer discomfort hours (overheating) & 1899.00 & 4529.00 & 6.70 \\
$\mathrm{~N}$ of winter comfort hours (heating) & 4380.00 & & 5110.00 \\
LIGHTNING DISCOMFORT & & & 52.20 \\
$\mathrm{~N}$ of lighting hours (year over) & 5726.00 & 726.00 & \\
IMPACT TO SUMMER COMFORT & & & \\
$\mathrm{N}$ of comfort hours in summer period & 477.00 & & \\
\hline
\end{tabular}

Best solution $\mathrm{s}_{1}$

Area $\left[\mathrm{m}^{2}\right]$

Overheating

Change in energy demand [ $k W h$ ]

Percentage variation of overheating [\%]

Percentage variation of energy demand [\%]
7.84

0.170

545.10

$-20.19$

15.93

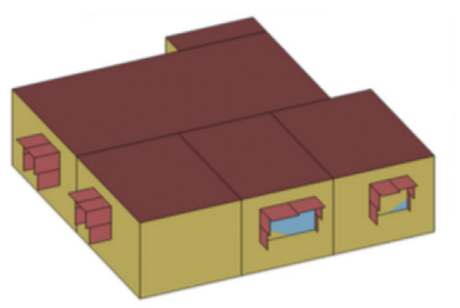

South window

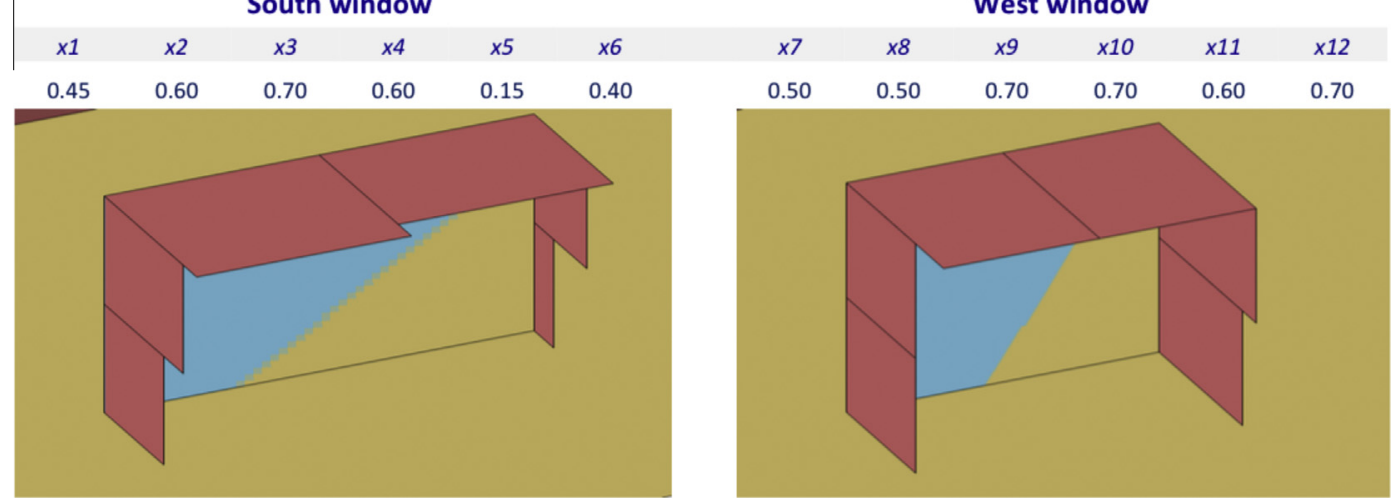

Fig. 8. Best solution in terms of overheating, size and change in energy demand.

Please cite this article in press as: Khoroshiltseva $\mathrm{M}$ et al. A Pareto-based multi-objective optimization algorithm to design energy-efficient shading devices. Appl Energy (2016), http://dx.doi.org/10.1016/j.apenergy.2016.05.015 


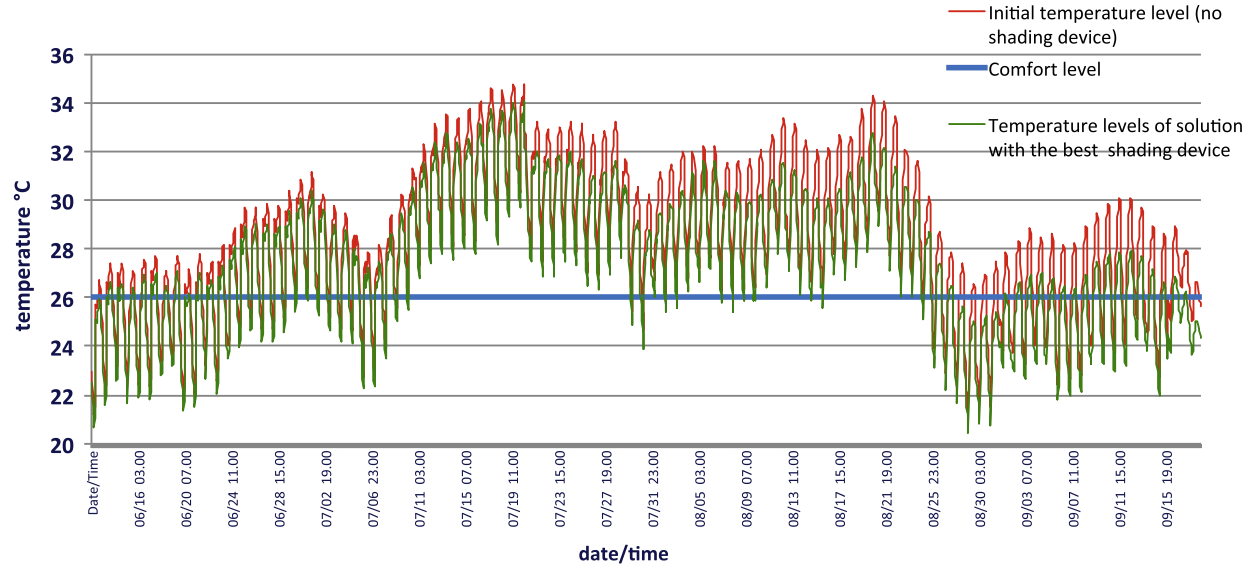

Fig. 9. Summer temperatures without the shading device (red line) and with the best selected shading solution (green line) achieved with the m-EDO approach. Blue line represents the standard comfort level temperature, over which overheating is defined. (For interpretation of the references to color in this figure legend, the reader is referred to the web version of this article.)

algorithm and the multi-objective optimization has been accomplished by the Pareto front. This m-EDO procedure has been coupled with EnergyPlus software for building dynamic simulations. Within this high dimensional case study, the results obtained proved that when there are conflictive objectives, m-EDO can be a powerful tool to select solutions taking into account not only the building energy saving but also the comfort level of inhabitants.

The best solution obtained by $\mathrm{m}$-EDO procedure is a configuration of shading devices with acceptable shape area of $7.84 \mathrm{~m}^{2}$; the solution provides the $20.19 \%$ reduction in overheating (reducing overheating to 0.170 ) and causes the $15.93 \%$ increase in energy consumption (generating $545.1 \mathrm{~kW} \mathrm{~h}$ change in energy demand). This increasing in energy demand is expected within the research due to the conflicting behavior of the optimization responses. Nevertheless, we consider that this impact on energy demand is less important with respect to positive contribution of overheating reduction. Furthermore, it is worth noting that our optimized solution provides nearly the same level of overheating with respect to the solution with maximum shading area ( 0.170 vs 0.169 respectively) while having the significantly smaller area of device $\left(7.84 \mathrm{~m}^{2}\right.$ vs $\left.9.98 \mathrm{~m}^{2}\right)$ and minor impact on energy demand (15.93\% vs $20.02 \%)$. At last, we would like to stress that this optimal solution, and the set of optimal solutions in the Pareto front, have been achieved evaluating just the small set of 1500 candidate solutions instead of the $14^{12}$ solution of the whole search space.

\section{Acknowledgments}

The research leading to these results has received funding from the European Union Seventh Framework Program (FP7/2007-2013) under grant agreement n. 314461 iNSPiRe. The European Union is not responsible for any use that may be made of the information contained in this document which represents the authors view. We acknowledge Roberto Fedrizzi, Coordinator of the project, for his useful contribution and advice. Thanks also to Davide De March, Matteo Borrotti, Bruno Bueno, Robert Weitlaner, Wilfried Pohl, and the anonymous referees for their helpful suggestions.

\section{References}

[1] Desideri U, Proietti S, Sdringola P, Taticchi P, Carbone P, Tonelli F. building solutions and certifications. Manage Environ Qual: Int J 2010;21(5):659-79.

[2] Proietti S, Desideri U, Sdringola P Zepparelli F. Carbon footprint of a reflective foil and comparison with other solutions for thermal insulation in building envelope. Appl Energy 2013;112:843-55.
[3] Bellia L, Marino C, Minichiello F, Pedace A. An overview on solar shading systems for buildings. Energy Procedia 2014;62:309-17.

[4] Proietti S, Desideri U, Sdringola P, Millucci M. An energy saving solution applied to the final use of electrical and lighting systems of school buildings managed by Perugia province. Int J Energy Environ Eng 2011;2(2):21-9.

[5] Sdringola P, Proietti S, Desideri U, Giombini G. Thermo-fluid dynamic modeling and simulation of a bioclimatic solar greenhouse with self-cleaning and photovoltaic glasses. Energy Build 2014;68(Part A):183-95.

[6] Kim G, Lim HS, Lim TS, Schaefer L, Kim JT. Comparative advantage of an exterior shading device in thermal performance for residential buildings. Energy Build 2012;46:105-11.

[7] Yun G, Yoon KC, Kim KS. The influence of shading control strategies on the visual comfort and energy demand of office buildings. Energy Build 2014;84:70-85.

[8] Freewan AA. Impact of external shading devices on thermal and daylighting performance of offices in hot climate regions. Sol Energy 2014;102:14-30.

[9] Huang Y Niu JL, Chung TM. Comprehensive analysis on thermal and daylighting performance of glazing and shading designs on office building envelope in cooling-dominant climates. Appl Energy 2014;134:215-28.

[10] Atzeri A, Cappelletti F, Gasparella A. Internal versus external shading devices performance in office buildings. Energy Procedia 2014;45:463-72. aTI 2013 68th Conference of the Italian Thermal Machines Engineering Association.

[11] Babaizadeh H, Haghighi N, Asadi S, Broun R, Riley D. Life cycle assessment of exterior window shadings in residential buildings in different climate zones. Build Environ 2015;90:168-77.

[12] Kirimtat A, Koyunbaba BK, Chatzikonstantinou I, Sariyildiz S. Review of simulation modeling for shading devices in buildings. Renew Sustain Energy Rev 2016;53:23-49.

[13] Stevanović S. Optimization of passive solar design strategies: a review. Renew Sustain Energy Rev 2013;25:177-96.

[14] Zemella G, De March D, Borrotti M, Poli I. Optimised design of energy efficient building façades via evolutionary neural networks. Energy Build 2011;43 (12):3297-302.

[15] Manzan M. Genetic optimization of external fixed shading devices. Energy Build 2014;72:431-40.

[16] Hadidi A. A robust approach for optimal design of plate fin heat exchangers using biogeography based optimization (BBO) algorithm. Appl Energy 2015;150:196-210.

[17] Blanco JM, Buruaga A, Rojí E, Cuadrado J, Pelaz B. Energy assessment and optimization of perforated metal sheet double skin façades through design builder; a case study in Spain. Energy Build 2016;111:326-36.

[18] Nguyen AT, Reiter S, Rigo P. A review on simulation-based optimization methods applied to building performance analysis. Appl Energy 2014;113:1043-58.

[19] Castillo L, Enríquez R, Jiménez M, Heras M. Dynamic integrated method based on regression and averages, applied to estimate the thermal parameters of a room in an occupied office building in Madrid. Energy Build 2014;81:337-62.

[20] Lee KS, Geem ZW. A new meta-heuristic algorithm for continuous engineering optimization: harmony search theory and practice. Comput Methods Appl Mech Eng 2005;194(36-38):3902-33.

[21] Manjarres D, Landa-Torres I, Gil-Lopez S, Ser JD, Bilbao M, Salcedo-Sanz S, et al. A survey on applications of the harmony search algorithm. Eng Appl Artif Intell 2013;26(8):1818-31.

[22] Deb K, Pratap A, Agarwal S, Meyarivan T. A fast and elitist multiobjective genetic algorithm: NSGA-II. IEEE Trans Evol Comput 2002;6(2):182-97.

[23] Carlucci S, Cattarin G, Causone F, Pagliano L. Multi-objective optimization of a nearly zero-energy building based on thermal and visual discomfort minimization using a non-dominated sorting genetic algorithm (NSGA-II). Energy Build 2015;104:378-94. 
[24] Baragona R, Battaglia F, Poli I. Evolutionary statistical procedures: an evolutionary computation approach to statistical procedures designs and applications. Springer Publishing Company, Incorporated; 2013.

[25] Borrotti M, De March D, Slanzi D, Poli I. Designing lead optimisation of MMP12 inhibitors. Comput Math Methods Med 2014;2014:1-8.

[26] Slanzi D, Poli I. Evolutionary bayesian network design for high dimensional experiments. Chemometr Intell Lab Syst 2014:135:172-82.

[27] Slanzi D, De Lucrezia D, Poli I. Querying bayesian networks to design experiments with application to $1 \mathrm{AGY}$ serine esterase protein engineering. Chemometr Intell Lab Syst 2015;149(Part A):28-38.

[28] Tzempelikos A, Athienitis AK. The impact of shading design and control on building cooling and lighting demand. Sol Energy 2007;81(3):369-82.

[29] Bellia L, Falco FD, Minichiello F. Effects of solar shading devices on energy requirements of standalone office buildings for italian climates. Appl Therm Eng 2013;54(1):190-201.

[30] Machairas V, Tsangrassoulis A, Axarli K. Algorithms for optimization of building design: a review. Renew Sustain Energy Rev 2014;31:101-12.

[31] Tuhus-Dubrow D, Krarti M. Genetic-algorithm based approach to optimize building envelope design for residential buildings. Build Environ 2010;45 (7):1574-81.
[32] Rapone G, Saro O. Optimization of curtain wall façades for office buildings by means of PSO algorithm. Energy Build 2012;45:189-96.

[33] Slanzi D, Borrotti M, De March D, Orlando D, Giove S, Poli I. Advances in artificial life and evolutionary computation. In: 9th Italian workshop, WIVACE 2014, Vietri sul Mare, Italy, May 14-15. Revised selected papers, Springer International Publishing, Cham; 2014. p. 13-25. [ch. Qualitative Particle Swarm Optimization (Q-PSO) for Energy-Efficient Building Designs]

[34] Fesanghary M, Asadi S, Geem Z. Design of low-emission and energy-efficient residential buildings using a multi-objective optimization algorithm. Build Environ 2012;49(1):245-50.

[35] Geem ZW, Kim JH, Loganathan GV. A new heuristic optimization algorithm: harmony search. Simulation 2001:76(2):60-8.

[36] Mahdavi M, Fesanghary M, Damangir E. An improved harmony search algorithm for solving optimization problems. Appl Math Comput 2007;188 (2):1567-79.

[37] Valian E, Tavakoli S, Mohanna S. An intelligent global harmony search approach to continuous optimization problems. Appl Math Comput 2014;232:670-84. 